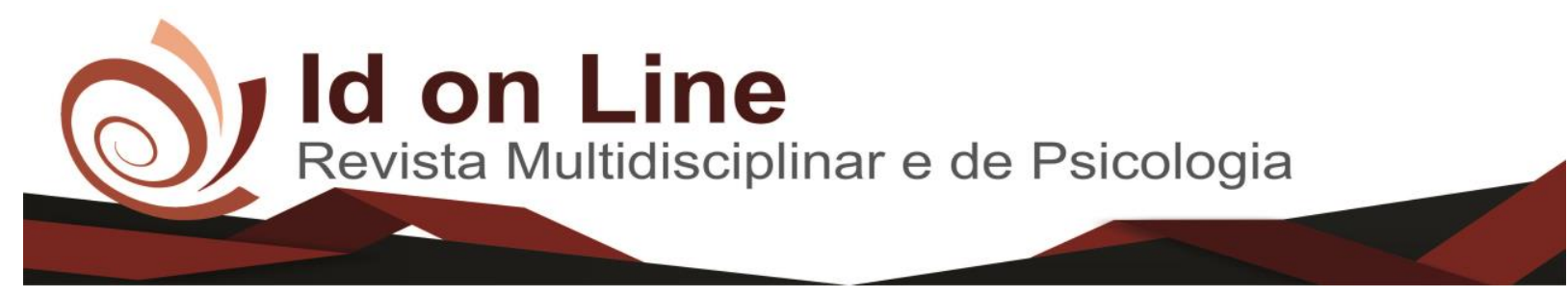

Artigo

\title{
Análise de Erros de Prescrição de um Programa de Internação Domiciliar de um Hospital Público
}

\author{
Mariana Alexandra Damascena Brandão ${ }^{1}$
}

\begin{abstract}
Resumo: O Atendimento Domiciliar refere-se a pacientes que disponham de problemas de saúde compensados e com complexidade ou incapacidade física de locomoção até uma unidade de saúde; ou pacientes que precisem de cuidados de menor intensidade, incluídos os de recuperação nutricional, de menor frequência de visitas, com menor necessidade de recursos de saúde e dentro da capacidade de atendimento de todos os tipos de equipes que compõem a atenção básica. A atenção farmacêutica domiciliar (AFD) compreende todas as práticas da atenção farmacêutica, tendo como diferencial a execução de um plano de adesão totalmente adaptado aos fatores sociais e familiares em que o usuário está inserido. Este estudo tem como objetivo, avaliar e quantificar o manejo das prescrições destinadas aos pacientes do programa de Internação Domiciliar de um hospital público interior da Bahia, verificando quais os erros encontrados com maior frequência. Trata-se de um estudo visando prescrições de pacientes internados entre o período de maio a julho de 2017. Os dados serão obtidos através de um formulário baseado no Programa Nacional de Segurança do Paciente do Instituto para Práticas Seguras no Uso de Medicamentos - ISMP. O formulário tem como finalidade o fornecimento de informações que possibilitem a tabulação dos dados através de técnicas estatísticas. Esses dados serão apresentados em forma de porcentagem.
\end{abstract}

Palavras-Chave: Assistência domiciliar; Prescrições; Paciente; Farmacêutico.

\section{Analysis of Prescription Errors of a Home Hospitalization Program of a Public Hospital}

\begin{abstract}
Home Care refers to patients who have paid health problems and complexity or physical incapacity to travel to the health unit; The needs of health resources and within the capacity of care of all types of equipment that make up basic care. Home pharmaceutical care (AFD) comprises all practices of pharmaceutical care, having as a differential the execution of a membership plan fully adapted to the categories and families in which the user is inserted. This study aims to evaluate and quantify the management of aortic benefits of the Home Hospitalization programs of an interior public hospital in Bahia, verifying which errors are most frequently encountered. This is a study aimed at prescribing patients inpatient between May and July 2017. Data are obtained through an online form There is no National Patient Safety Program of the Institute for Safe Practices in the Use of Medications ISMP. The purpose of the form is to provide information that enables tabulation of the data through statistical techniques. This data is presented as a percentage.
\end{abstract}

Key Words: Home care; Prescriptions; Patient; Pharmaceutical.

\section{Introdução}

A OMS (Organização Mundial da Saúde) preconiza a internação domiciliar como diretriz para a equipe básica de saúde, destacando que ela não substitui a internação hospitalar e que deve ser sempre utilizada no intuito de humanizar e garantir maior conforto à população.

\footnotetext{
${ }^{1}$ Graduanda do curso de Farmácia da Faculdade Independente do Nordeste - FAINOR
} 
Sendo realizada quando as condições clínicas do usuário e a situação da família o permitam. (OMS, 2012 apud RODRIGUEZ, 2013).

Segundo Giacomozzi e Lacerda (2006), a assistência domiciliar à saúde "é uma categoria da atenção domiciliar à saúde que pode ser também denominada atendimento ou cuidado domiciliar e baseia-se na plena interação do profissional com o paciente, sua família e com o cuidador, quando esse existe. Ela constitui um conjunto de atividades de caráter ambulatorial, programadas e continuadas desenvolvidas em domicílio, e pode ser instrumentalizada pela visita ou internação domiciliar”. (Giacomozzi; Lacerda, 2006).

A presença do farmacêutico atuando juntamente com a equipe multidisciplinar é de fundamental importância para um tratamento farmacoterapêutico eficiente, pois engloba os serviços de Atenção Farmacêutica, Assistência Farmacêutica, Farmacovigilância, Farmácia Clínica e Auditoria Farmacêutica (PLANAS et al., 2005 apud OLMEDILHA; CAPPELARO, 2013).

Dessa forma, a facilidade de acesso ao farmacêutico, sua formação técnica com um amplo conhecimento sobre medicamentos e, a necessidade de seu melhor aproveitamento enquanto profissional da saúde, permite que o mesmo faça parte de uma equipe multidisciplinar (DADER, 1999 apud OLMEDILHA; CAPPELARO, 2013).

Contudo, apesar do profissional farmacêutico ter todos os requisitos cabíveis para fazer parte de uma equipe multidisciplinar conforme portaria $n^{\circ} 272$ de 1998 do Ministério da Saúde (Brasil, 1998), na internação domiciliar, o farmacêutico ainda não conseguiu seu espaço, visto que, a referida portaria não contempla o profissional.

Na Atenção Farmacêutica Domiciliar, todas as ações construídas com o paciente, com o intuito de alcançar o objetivo terapêutico, são registradas incluindo a educação em saúde, encaminhamento a outros profissionais da saúde, intervenções na farmacoterapia, medidas não farmacológicas como incentivo à atividade física e à reeducação alimentar (BARROS, 2005 apud OLMEDILHA; CAPPELARO, 2013). Assim, fica evidenciado a importância da presença deste profissional no processo de acompanhamento desses pacientes.

De acordo com a Resolução $n^{\circ}$. 357/01 (BRASIL, 2001) o farmacêutico é responsável pela avaliação farmacêutica do receituário e somente será aviada/dispensada a receita que apresentar as informações exigidas na resolução tais como: nome e endereço residencial do paciente, forma farmacêutica, posologia, apresentação, método de administração e duração do tratamento, data, assinatura e carimbo do profissional, endereço do consultório e o número de 
inscrição no respectivo Conselho Profissional, ausência de rasuras e emendas, prescrição a tinta em português, em letra de forma, clara e legível ou impressão por computador, dentre outras. (BRASIL, 2001 apud VALADÃO et al., 2009).

É reconhecido que as prescrições têm papel ímpar na prevenção de erros de medicação e, sabe-se que tais erros podem decorrer de prescrições ambíguas, ilegíveis ou incompletas, ocasionando sérios danos ao paciente. Winslow et al., (1997) informam que o risco de erros de medicação aumenta na medida em que enfermeiros e outros profissionais não conseguem ler corretamente as prescrições. (VALADÃO et al., 2009).

Muitos dos erros relacionados a prescrição médica pode atrapalhar toda a farmacoterapia do paciente ou até mesmo levar a um erro mais grave levando o paciente até mesmo a óbito. Por isso a importância de uma avaliação das prescrições com o profissional adequado para tal fim.

No Brasil existem normatizações que regem as prescrições definidas através de Portarias, Leis e Resoluções. No tocante ao aspecto legal da prescrição em nosso País, a publicação da Lei $n^{\circ}$. 5991/73 (BRASIL, 1973) que traz em seu artigo 35 exigências quanto à legibilidade, existência dos nomes dos medicamentos por extenso, dosagem, posologia, data e assinatura do profissional prescritor. (VALADÃO et al., 2009).

Esse Presente artigo tem como objetivo avaliar os principais problemas relacionado a prescrições médicas do serviço do atendimento domiciliar sem intervenção farmacêutica de uma um hospital público do interior da Bahia.

\section{Metodologia}

O presente estudo visa buscar informações, caracterizado por um estudo transversal, retrospectivo, descritivo, analítico qualitativo e quantitativo dos dados obtidos.

A pesquisa foi realizada em uma amostragem não probabilística, onde a população de estudo serão as prescrições do serviço de internação domiciliar entre os meses de maio à julho de 2017.

Solicitado autorização para a realização da pesquisa, após aceitação da mesma, terá como campo base para coleta o Hospital Geral de Vitória da Conquista, que atende em caráter de emergência ou não, pelo Sistema Único de Saúde (SUS), localizado na região sudoeste no 
interior da Bahia sendo uma referência de atendimento para toda a região e para o norte de Minas Gerais.

Serão analisadas as prescrições dos pacientes internados no serviço de internação domiciliar entre os meses de maio à julho de 2017visando características como: percentuais de abreviaturas, prescrições ilegíveis, prescrições com falha de identificação quanto ao nome do paciente, do prescritor e da instituição. Obtendo os dados necessários, serão ilustrados através de tabelas.

As informações foram analisadas de maneira quantitativa e qualitativa os principais problemas relacionados a prescrição no serviço de atendimento domiciliar.

O formulário utilizado foi baseado na informação presente em "Programa Nacional de Segurança do Paciente: indicadores para avaliação da prescrição, do uso e da administração de medicamento" do Instituto para Prática Segura do Uso de Medicamentos - ISMP.

\section{Resultados e Discussão}

Tabela 1 - Relação do número total de medicamentos por prescrição do programa de Internação Domiciliar no período de 03/05/2017 à 25/07/2017.

\begin{tabular}{l|l}
\hline Número & Medicamentos \\
\hline $0-5$ & 52 \\
\hline $6-10$ & 96 \\
\hline $11-15$ & 70 \\
\hline $16-20$ & 1 \\
\hline $21-25$ & 3 \\
\hline
\end{tabular}

Fonte: Próprio autor.

A maioria das prescrições tem entre 6 a 15 medicamentos (mostrado na tabela acima), isso corresponde a uma polifarmácia. A polifarmácia é definida como a utilização de cinco ou mais medicamentos.

Tabela 2 - Relação do número de medicamentos prescritos com erro de dosagem do programa de Internação Domiciliar.

\begin{tabular}{c|c|c}
\hline $\begin{array}{c}\mathrm{N}^{\circ} \text { de } \\
\text { medicamentos } \\
\text { prescritos }\end{array}$ & $\begin{array}{c}\mathrm{N}^{\circ} \text { de } \\
\text { erros de } \\
\text { dosagem }\end{array}$ & $\begin{array}{c}\text { Percentual } \\
(\%)\end{array}$ \\
\hline 1.931 & 542 & $28 \%$ \\
\hline
\end{tabular}

Fonte: Próprio autor. 
Prescrever dosagem inadequada de algum medicamento coloca em risco a saúde do paciente e a eficiácia do tratamento. Esquecer de indicar a dosagem do medicamento também é comum, neste caso, o farmacêutico ficará impossibilitado de fornecer o medicamento ao paciente, sendo preciso entrar em contato com o prescritor. Conforme a tabela 2, 28\% dos medicamentos prescritos encontra-se com erro de dosagem.

Tabela 3 - Relação do número de medicamentos prescritos com abreviaturas contraindicadas do programa de Internação Domiciliar

\begin{tabular}{c|c|c}
\hline $\begin{array}{c}\mathrm{N}^{\circ} \mathrm{de} \\
\text { medicamentos } \\
\text { prescritos }\end{array}$ & $\begin{array}{c}\mathrm{N}^{\circ} \mathrm{de} \\
\text { abreviaturas } \\
\text { contraindicadas }\end{array}$ & $\begin{array}{c}\text { Percentual } \\
(\%)\end{array}$ \\
\hline 1.931 & 353 & $18 \%$ \\
\hline
\end{tabular}

Fonte: Próprio autor.

O uso de abreviaturas contraindicadas podem ocasionar erros na hora da dispensação ou até mesmo na administração do medicamento. Com isso pode levar a uma piora no quadro do paciente ou o um atraso nos resultados positivos do tratamento. De acordo com a tabela 3, 18\% dos medicamentos prescritos contém algum tipo de abreviatura contraindicada.

Tabela 4 - Relação do número de medicamentos prescritos que não estão conforme ao $\mathrm{DCB} / \mathrm{DCI}$

\begin{tabular}{c|c|c}
\hline $\begin{array}{c}\mathrm{N}^{\circ} \text { de } \\
\text { medicamentos } \\
\text { prescritos }\end{array}$ & $\begin{array}{c}\mathrm{N}^{\circ} \text { de } \\
\text { medicamentos } \\
\text { não conforme } \\
\text { com DCB/DCI }\end{array}$ & Percentual (\%) \\
\hline 1.931 & 538 & $28 \%$ \\
\hline
\end{tabular}

Fonte: Próprio autor.

Denominação Comum Brasileira (DCB) é a denominação do fármaco ou princípio farmacologicamente ativo aprovada pelo órgão federal responsável pela vigilância sanitária descrito na Lei $n^{\circ}$ 9.787/1999.Já a A Denominação Comum Internacional (DCI) é uma adaptação proposta pela Organização Mundial de Saúde para substâncias ativas dos medicamentos, de acordo com regras definidas, que não pode ser objeto de registo de marca ou de nome, conforme lista publicada periodicamente por esta Organização.

Como explícito na tabela 4, $28 \%$ dos medicamentos prescritos não estão de acordo com a DCB e DCI. 
Tabela 5 - Relação do número de medicamentos prescritos sem a forma farmacêutica

\begin{tabular}{c|c|c}
\hline $\begin{array}{c}\mathrm{N}^{\circ} \text { de } \\
\text { prescritos }\end{array}$ & $\begin{array}{c}\mathrm{N}^{\circ} \text { de } \\
\text { medicamentos } \\
\text { prescritos sem } \\
\text { a forma } \\
\text { farmacêutica }\end{array}$ & $\begin{array}{c}\text { Percentual } \\
(\%)\end{array}$ \\
\hline 1.931 & 668 & $35 \%$ \\
\hline
\end{tabular}

Fonte: Próprio autor.

A forma farmacêutica se correlaciona à via de administração que vai ser utilizada. A exclusão da mesma pode acarretar a dispensação do medicamento incorreto. Há $35 \%$ dos medicamentos prescritos estão apresentados sem a forma farmacêutica.

Tabela 6 - Relação do número de medicamentos prescritos com erros

\begin{tabular}{c|c|c}
\hline $\begin{array}{c}\mathrm{N}^{\circ} \text { de } \\
\text { preascritos } \\
\text { prestos }\end{array}$ & $\begin{array}{c}\mathrm{N}^{\circ} \text { de } \\
\text { medicamentos } \\
\text { prescritos com } \\
\text { erros }\end{array}$ & $\begin{array}{c}\text { Percentual } \\
(\%)\end{array}$ \\
\hline 1.931 & 1.258 & $65 \%$ \\
\hline
\end{tabular}

Fonte: Próprio autor.

Conforme a tabela 6 foi constatado que mais da metade das prescrições apresentam algum erro relacionado ao ato de prescrever. Por isso, torna-se essencial a presença do profissional farmacêutico para analisar as prescrições para que não haja uma dispensação incorreta do fármaco.

\section{Conclusão}

Segundo o contexto do estudo, regulamente é encontrado erros no ato de prescrever. A importância de um profissional habilitado, no caso o farmacêutico. Inserido na equipe multidisciplinar no programa de Internação Domiciliar em avaliar as prescrições de forma correta pode reduzir a incidência de erros, podendo ajudar em uma farmacoterapia adequada para o paciente. 


\section{Referências}

AMARAL, Nilcéia Noli do. et al. Assistência Domiciliar à Saúde (Home Health Care): sua História e sua Relevância para o Sistema de Saúde Atual, Rev. Neurociências, São Paulo, 9(3): 111-117, 2001

BOVO, Fernanda et al. Atenção Farmacêutica: papel do farmacêutico na promoção da saúde. Bio saúde, v. 11, n. 1, p. 43-56, Londrina, jan./jun. 2009.

FABRÍCIO, Susete Cristina Coelho et al., Assistência domiciliar: a experiência de um hospital privado do interior paulista Rev. Latino-Am. Enfermagem. Ribeirão Preto, vol.12 no.5, 2004.

GIACOMOZZI C.M.; LACERDA M. R. A prática da assistência domiciliar dos profissionais da estratégia de saúde da família. Texto Contexto Enferm, Florianópolis, 2006 Out-Dez; 15(4): 645-53, 2006. Disponível em: 〈http://www.scielo.br/pdf/tce/v15n4/v15n4a13.pdf >. Acesso em: 03 de maio de 2017.

JACOBSEN, Thiely Fernandes et al. Análise de erros de prescrição em um hospital da região sul do Brasil. Rev. Bras. Farm. Hosp. Serv. Saúde, São Paulo v.6 n.3 23-26 jul./set. 2015.

LACERDA, Maria Ribeiro et al. Atenção à saúde no domicílio: modalidades que fundamentam sua prática, Saude Soc. vol.15 no.2 São Paulo May/Aug, 2006.

OLMEDILHA R. S.; CAPPELARO A.M.S. O papel do farmacêutico na atenção domiciliar. Rev. Pesq. Inov. Farm. 5(1), 2013, 31-37, 2013.. Disponível em: <http://www.pgsskroton.com.br/seer/index.php/RPInF/article/download/39/33>. Acesso em: 03 de maio de 2017.

RODRIGUEZ M. I. F. Internação domiciliar: avaliações imperativas implicadas na função de cuidar. Psicologia Rev. São Paulo, volume 22, n.2, 197-212, 2013. Disponível em: <https://revistas.pucsp.br/index.php/psicorevista/article/view/17989/13360> Acesso em: 03 de maio de 2017.

VALADÃO, A. F et al., Prescrição médica: um foco nos erros de prescrição. Rev. Bras. Farm,. 90(4): 340-343, 2009. Disponível em: <http://rbfarma.org.br/files/pag_340a343_prescricao_medica_261_904.pdf >. Acesso em: 03 de maio de 2017.

RÊGO, Marília Moreno do; Coromella, Larissa. O papel da análise farmacêutica da prescrição médica hospitalar. Caderno Saúde e Desenvolvimento. vol.7 n.4 | jan/jun - 2015.

OLIVEIRA S. A. R.; Junges F., Papel do profissional farmacêutico no âmbito da assistência farmacêutica CCE - Centro de Capacitação Educacional, Recife, 2015.

PAZIN FILHO, Antônio et al., Princípios de prescrição médica hospitalar para estudante de medicina. Rev. FMRP USP. Ribeirão Preto, São Paulo, 46(2):183-94, 2013. 


\section{Como citar este artigo (Formato ABNT):}

BRANDÃO, Mariana A. D. Análise de Erros de Prescrição de um Programa de Internação Domiciliar de um Hospital Público. Id on Line Revista Multidisciplinar e de Psicologia, 2017, vol.11, n.38, p. 287-294. ISSN: 1981-1179.

Recebido: 26.10 .2017

Aceito: 27.10 .2017 